\title{
Resolving family conflicts
}

\author{
ROBERT O. BLOOD, JR.
}

University of Michigan

\section{Introduction}

Aside from the inner conflicts of the individual person, the family is the smallest arena within which conflict occurs. Since the scale of conflict is so much smaller than occurs between the great powers of the world, can the ways in which families resolve their conflicts ever apply to international conflict?

The present article deals primarily with the inherent characteristics of family conflict, some of them diametrically opposite to international conflict. Nevertheless, the study of small-scale conflict seems most likely to yield new hypotheses relevant to large-scale conflict if the family is studied on its own terms. Were we to limit ourselves to facets of obvious relevance, new ways of looking at international conflict might be missed. In any case, a general theory of conflict must eventually embrace all ranges of social systems, from the largest to the smallest. Hence family conflict has potential interest for its similarities with, and its differences from, large-scale conflict.

Conflict is a widespread and serious problem in the contemporary American family. Roughly, one marriage in every four ends in divorce, which is usually preceded, and often caused, by the failure of family members to avoid or solve their conflicts. Many additional families survive their periods of stress only at great cost to their physical and mental health. Many a husband's ulcers, a wife's headaches, and a child's nervous tics are traceable to domestic tension and warfare.

How does it happen that conflict afflicts so many families?

\section{Sources of Family Conflict}

Families everywhere tend to have certain characteristics which lay them open to potential conflict.

\section{COMPULSION}

For one thing, a family is not a voluntary organization (except for the husband and wife). Children do not choose their parents. When the going gets tough, they cannot resign their membership. Even the parents are under heavy pressure to stick with the group no matter what.

Such involuntary participation tends to intensify conflict, once it originates. Because they have to continue living in the same house year in and year out, family members can develop deep antipathies for one another. What began as a mere conflict of interest easily turns into emotional hatred through the accumulation of grievances between two family members. Once such hostility has arisen, conflict often becomes self-perpetuating.

\section{INTIMACY}

The conflict potentialities inherent in the involuntary membership of the family are accentuated by the intimacy of contact within the family. In school or church or business physical distance and social formality are 
maintained at some minimum level. Moreover, contact is restricted to a limited range of relationships, such as teacher-pupil, priestparishioner, or boss-secretary. ${ }^{1}$

By contrast, relationships within the family are functionally diffuse. Family members lay all sorts of claims on one another for economic maintenance, recreational companionship, sexual responsiveness, sympathetic understanding, love and affection, etc. The comprehensiveness of these claims points to additional potential sources of conflict.

When conflict does occur within the family, it lacks the restraint imposed by concern for public opinion. If a man's home is his castle, it is also the place where his dungeons of despair are. A man who would never strike a women in public finds his fury uncontrollable when goaded by a nagging wife behind closed doors. A child who would be patiently admonished in a public park needs a pillow in his pants for the same behavior at home. The very privacy which makes possible the most uninhibited embrace within the bedroom permits an equally uninhibited tonguelashing. Intimacy of contact, therefore, contributes to both the extensity and the intensity of conflict within the family.

\section{SMALLNESS}

While families everywhere are characterized by compulsory membership and intimate contact, the American family's small number of children further magnifies the problem of conflict, especially between siblings. In a large family, one child's share of his mother's attention and affection is so limited that it matters little whether he has it or not. In a two-child family, however, one child can monopolize the parent simply by vanquishing his sole sibling. Under these circumstances sibling rivalry becomes acute.

1 This is what Talcott Parsons calls "functionally specific relationships" (8).
Similarly, among three siblings, the inherent instability of the triad typically leads the two older children to battle for the pawn. Again limited size dictates who the potential enemy shall be, makes him highly visible in the small group, and leads to the development of long-term feuds.

\section{CHANGE}

The above family features would not be so bad were it not for the rapidity with which the family situation changes. Given fixed ingredients, a stable equilibrium might be sought. But families change so fast that a moving equilibrium is the best that can be hoped for.

Families change rapidly in size. Census figures show that newlyweds typically have hardly more than a year in which to work out their marital relationship before it is altered by the nausea of pregnancy. Then the children come every two years-bing, bing, bing. A decade and half later they leave for college or its working-class equivalents with similar rapidity (5).

Meanwhile the family may have maintained the same size, but the needs of its members were rapidly changing. Every time a new child starts to crawl, to climb, to wander across the street, to go to school, to experience puberty, or to drive a car, the pattern of family living must be readjusted. The changing "developmental tasks" of growing individuals create corresponding "family developmental tasks." Even parents' needs change as, for example, when the mother loses her figure or the father fails to get the raise he expected. Since the American family specializes in personality development and personal need fulfilment, such individual changes tend to disrupt the family equilibrium.

Given so many potentialities for conflict, what mechanisms exist for preventing the total disruption of what is so of ten called the "basic unit" in society? 
Normative Mechanisms for Preventing Family Conflct

No society can afford to turn its back on family conflict. The family is too indispensable a unit of social structure and too necessary a means for the transmission of culture to the oncoming generation to be allowed to fall apart.

Consequently, every society tends to develop patterned ways of inhibiting the emergence of conflict. With the passage of time, these mechanisms tend to acquire the force of norms. That is, social pressures are mobilized to increase the likelihood that these mechanisms will be utilized, and social sanctions are imposed on those who violate them.

Different preventive mechanisms are found in various societies, depending partly on the points at which their family system is especially vulnerable to conflict. The following analysis classifies particular taboos and requirements in broad categories of general interest.

1. Avoidance of probable sources of confict.-Many societies have devices for keeping apart potential or actual family members who otherwise would be likely to come into conflict with each other. By "potential family members" are meant couples who are not yet married. Societies have many ways of screening out those most predisposed to conflict. The traditional "publishing of the banns" allowed triple opportunities for objections to be raised to an inappropriate partnership. The formal engagement notifies parents and friends of the couple's intentions, providing a last opportunity for pressures to be brought to bear in disapproved cases. Studies of broken engagements show that such pressures often successfully prevent what would presumably be conflict-laden marriages (4, pp. 275-76).

Studies of "mixed marriages" of many sorts show a greater incidence of conflict due to the contrasting cultural values, expectations, and behavior patterns of the partners (6). Church organizations mobilize their resources to discourage interfaith marriages, and informal social pressure tends to prevent heterogamous marriages across racial, national, or class boundaries. Although a majority of all mixed marriages succeeds, such social pressures presumably break up in advance those mixed marriages which would be least likely to succeed.

New preventive mechanisms in our society are marriage education and premarital counseling. An estimated 10 per cent of American college students now take a course in preparation for marriage, one of whose main purposes is to rationalize the process of mate selection through emphasizing numerous ways of testing compatibility (3). Most such courses operate on the premise that young people are liable to contract incompatible marriages if they are not careful. Hence the chief value of compatibility testing is to detect which relationships are incompatible.

One of the main functions of premarital counseling, similarly, is to provide couples in doubt with an opportunity to look objectively at the conflicts already apparent in their relationships and to provide them with emotional support as they go through the process of deciding to avoid each other in the future.

Two legal moves designed to avoid domestic difficulties are almost universal among the fifty states. One of these is the five-day waiting period between the time of applying for a marriage license and the date of the wedding. This provides an opportunity for those intoxicated with wine or perfume to sober up and reconsider. Similarly, the age at which couples can marry without the blessing of their parents has been increased to eighteen for the bride and twenty-one for the groom. Since teen-age marriages have a conspicuously higher divorce rate, raising the minimum age probably reduces the number of marriages which get off to a bad start. 
Once the marriage has been contracted, one of the widespread sources of difficulty is the in-law relationship. Since marriage involves a drastic shift in allegiance from parents to spouse, newlyweds often have ambivalent feelings which are reflected in interspousal jealousy and conflict. This marital tension makes it correspondingly difficult for couples to get along with their parents-in-law.

Our society reduces friction in this area by warning couples not to move in with their in-laws if they can possibly avoid doing so. Some societies prescribe even stricter avoidance by restricting or prohibiting social intercourse with the mother-in-law. Especially taboo is the familiarity of joking with the mother-in-law. Reserve and formality are frequently required. Sometimes complete avoidance is the rule-one must neither talk with nor even look at the mother-in-law. ${ }^{2}$ Although there may be social losses, such mechanisms of avoidance effectively rule out the possibility of conflict between potentially hostile individuals.

2. Allocation of rights and duties to particular roles.-A second way in which societies prevent conflict is by distributing the authority, privileges, and responsibilities of family members according to a fixed pattern. In so doing, these societies predetermine the outcome. In fact, they short-circuit the conflict process completely because they take the issue out of the area of legitimate controversy. Henceforth only in socially deviant families does conflict ever occur over the allocated matters. For example, the incest taboo allocates sexual privileges exclusively to the husband and wife. Murdock and other anthropologists believe that the reason why this allocation pattern is found universally is because it is essential to family harmony (7, pp. 295-96). It functions to prevent sexual

2 Most of the cross-cultural examples in this paper are drawn from George P. Murdock (7). jealousy and rivalry within the family which would exist if more than one member of the family were allowed access to the same sexual partner.

Similarly, authority in the family is seldom distributed evenly among family members or (vaguer yet) left to each new family to decide for itself. Almost every society centralizes legitimate power in one role, usually that of the father. This is not to say that the wife and children are necessarily excluded from consultation in the decision-making process. Indeed, consideration for the wishes of the members of his family may be enjoined on the patriarch. However, a patriarchal family system specifies that in a showdown-when husband and wife cannot agree on mutually exclusive alternatives-the husband's wishes should prevail. The beauty of this system lies not in male superiority but in the fact that a ready out is available from any deadlock which may arise. It could as easily be the wife (and is in a few societies). It is handy, however, to have a way of avoiding prolonged crises within the family.

Authority need not be allocated entirely to one role. Each partner may have certain areas of family living in which he has autonomous jurisdiction. For example, most Detroit husbands make the final decision about what car to buy, while the typical wife decides how much money to spend on food for the family. ${ }^{3}$ Whenever people grow up expecting the husband or the wife to make decisions on their own in the "proper" areas, those areas are effectively removed from the domain of conflict.

Herein lies the problem of the democratic family. Whenever two or more family members believe they ought to share in making a certain decision, they have added another

3 All references to Detroit families are drawn from the writer's 1955 interview study of 731 housewives (a representative sample of the Detroit Metropolitan Area) (2). 
potential conflict to their portfolio. The American family has been drifting in the direction of a "companionship" ideology, which specifies that an increasing number of decisions should be made jointly. A good example is the family vacation, which 66 per cent of all Detroit housewives report is planned fiftyfifty. In the long run, mutual planning is likely to produce results which at least partly please both partners. And, according to our democratic philosophy, this is an improvement over the old system of fully pleasing one partner at the expense of the other.

But the process may be painful. The trend "from institution to companionship" has opened a whole Pandora's box of potential new conflicts. These do not necessarily materialize; under the classical patriarchate, they could not.

The blurring lines in the division of labor similarly open the way to more conflict. In a time when women did the dishes without question, dish-washing was not a topic for cartoons (symptoms of sore spots in any society). But, as men and women alike begin to wonder whether and how much men should help out in the kitchen, a new area of controversy is added to the list. Thus a clearly defined division of labor, like a clearcut allocation of authority, may be a social device for preventing conflict.

3. Equality of treatment within the family. -The allocation of authority to particular members of the family does not mean the right to wield it arbitrarily. Despotic power creates unrest within the body domestic just as much as in the body politic. To prevent such unrest, the centralization of authority must be coupled with a bill of rights for the weaker family members to protect them from discriminatory treatment.

The exercise of power within the family takes two forms: (1) influencing or forcing the individual to alter his behavior (either by doing something he does not want to do or by stopping what he would like to do) and (2) granting or withholding favors. Even though the ability to exercise both types of power may be vested primarily (or ultimately) in the father, it is well to remember that the mother is a powerful figure for her children, especially when they are small. Indeed, every member of the family has the power to grant or withhold his attention, love, and respect regardless of how weak he may be in other respects. Therefore, when we speak of the necessity of equal treatment, we are not referring to the father alone.

How does equal treatment manifest itself in the family? The illustrations are endless. If Johnnie gets a story before he goes to bed, so must Jane. If he has to pick up the livingroom floor, she has to be forced to do her share. If Tom gets to use the family car on Friday, then Dick has a right to it on Saturday. Children and parents alike recognize the justice of such claims and can appeal to the moral value of fair play to secure equality. Insofar as equality is achieved, conflict tends to be avoided.

The administrative problem is complicated, however, by the fact that siblings are rarely of the same age. As a result, the principle of equality cannot always mean uniformity of treatment at any particular time. If John stays up until 9:00 P.M., that does not mean Jane can-being two years younger, she must have extra sleep. Accepting such seeming discrepancies is not easy for younger children. However, parental emphasis on the idea that, "when you are ten years old, you will be able to stay up until 9:00 P.M. too" is often effective.

Age-graded equality is likely to prevent conflict especially well when the system for moving from one notch to the next is clearly understood by all concerned. For instance, if every child's allowance automatically increases a nickel on his birthday, the younger siblings can feel confident that they will re- 
ceive their "just deserts" when the proper time comes.

In the light of what was said earlier about the conflict-preventing function of the incest taboo, it is apparent that the custom of polygyny presents very serious problems. Whenever there are several wives but only one husband, the danger of jealousy and conflict among the wives is very acute. It is not surprising, therefore, that polygynous societies have devised all three types of measures for preventing the outbreak of such conflict. (1) Avoidance is achieved by placing each wife and her children in a separate hut. (2) Authority over subsequent wives is usually allocated to the first wife-her position is thereby less threatened, and the loss of exclusive wifehood is offset by the addition of maid service. (3) More important for our present purposes is the common requirement that the man treat his wives equally, that he not play favorites among them. This often takes the form of requiring the husband to follow a strict schedule of rotation among his wives, spending an equal number of nights with each in turn. No society can effectively control the warmth or coolness with which he treats an unpopular wife; however, this merry-go-round rule at least spares her the humiliation of public knowledge of her husband's disfavor.

Equality of treatment is not an easy achievement, especially where intangibles like affection and attention are involved. Only the childless couple can completely avoid conflict from this source. As soon as the first child arrives, competition for the time and interest of the mother is created. Since she does not have enough time to go around, she must be prepared to say to her son, "I played with you last night, so tonight you should not object to my going out with your father." Even the child whose oedipal wishes have not been effectively resolved may accept such a statement if the norm of family equality has been adequately learned.

Avoidance, allocation, and equality-not separately but in combination-are the inventions which cross-cultural research shows to have been practical ways by which societies have prevented family conflict.

\section{Instrumental Mechanisms for Resolving Family Conflicts}

Despite the existence of preventive mechanisms, and wherever those mechanisms do not exist, conflict occurs. The means of ending those conflicts seem far less often culturally prescribed. Rather there seem to be a number of optional procedures, in the United States at least, which are available to families as ways out of their dilemmas. These mechanisms are instrumental in the sense that they can be employed as means to achieve certain ends, if the family so desires.

1. Increased facilities for family living.When conflict results from scarce facilities, it is sometimes possible to satisfy both the conflicting parties by increasing the resources at the family's disposal. For example, sibling jealousy often originates from the mother's preoccupation with the new baby on her return from the hospital. An extra "mother" in the form of grandmother or nurse relieves the real mother of part of her work load so that she can give more attention to her displaced child.

Those societies with an extended family system have built-in grandmothers, aunts,' and cousins who flexibly replace the mother when her attention is unavailable. Ethnographers report a general lack of sibling rivalry under this multiple mothering.

Conflict in the American home often centers around the use of scarce physical facilities. The current trends to a second car, a second television set, and a second telephone result not only in increased profits for the 
corresponding manufacturers but in decreased tension for family personnel who can now use parallel facilities simultaneously instead of having to compete for control of single channels. Similarly, the new-fangled recreation room provides the rest of the family with a retreat when daughter decides to throw a party in the living room, taking the tension off competition for "the only room in the house where I can entertain my friends."

2. Priority systems for the use of limited facilities.-When enlargement of facilities is impossible, family conflict often becomes chronic-there is perpetual tension between family members, perennial jockeying for position, and fear that the competitor is getting ahead or taking advantage. Such feuding can often be seen among young children and is difficult to end by rational means. With older family members, war weariness may eventuate in a desire for peace at any price. Conflict may then be ended by facing the issues and arriving at decisions in some fashion or other.

The product of such decision-making is often a priority system governing the use of the scarce facility. If the bone of contention is the television set, a schedule for the whole week, born of a major showdown, may take the place of petty conflict "every hour on the hour." If the scarcity has been financial, the record of decisions takes the form of a budget. Here the mutual recriminations sparked by overdrawn bank accounts can be obviated by advance planning about where the money is to be spent.

The beauty of a budget, as of any other system, is that personal control ("I say you must") is replaced by impersonal control ("The budget says you must"). The process of agreeing on a budget is still liable to plenty of conflict, but, once formulated, a budget tends to divert attention from the hostile antagonist to the operational code.
3. Enlargement of areas of autonomy.Analogous in many ways to the method of effecting an absolute increase in the facilities available to family members is the choppingup of existing facilities into smaller units which can then be made available exclusively to different members of the family. This results in a relative increase in the facilities at the disposal of the individual without the necessity of securing the consent of other family members. Hence potential conflict is avoided. For example, some couples plague themselves with difficulty by trying to arrive at joint decisions about the disposition of the scarce commodity of money. Worse yet, each partner may endlessly reproach the other for the petty expenditures he has already made. Such bickering can be ended by granting each partner an allowance to be spent as he sees fit without the necessity of accounting to the other for his whims and fancies. This innovation correspondingly restricts the area in which decision-making (and potential conflict) must occur to more critical areas of financial management.

The method of granting autonomy is not limited, however, to the use of scarce facilities. The problem of adolescent-parent conflict may be resolved by judicious increases in the amount of autonomy granted the teenager. Some parents clash head-on with their high-school sons and daughters in attempting to curb their adoption of the latest fads in dress and speech. Certainly, the easiest way out of this dilemma is to recognize that teenagers are old enough to decide for themselves what to wear and how to talk.

Similarly, conflict may result from undue stress on total-family activities. The mother who worries about finding recreation which both her four-year-old and her fourteen-yearold will enjoy may be troubling herself unduly, since almost anything she chooses evokes dissent from one child or the other. 
Autonomy under such circumstances need not mean a complete atomization of the family but simply a willingness of a subgroup within the family to enjoy singing nursery rhymes without feeling the necessity of compelling disinterested members to join.

4. Safety valves for reducing tension between family members.-Insofar as conflict within the family is precipitated or accentuated by accumulated interpersonal resentment, various means are available for reducing the level of this tension. Vacations are one such resource. Of course, a family may find plenty of things to quarrel about on a vacation, but at least they are new issues. As far as the old problems are concerned, a change of scenery makes it possible to forget about them for a while, and on return they may even have lost their power to provoke antagonism.

A change in personnel may be just as effective. Adding a pal or two for the morning play period may so restructure relationships within the sibling group that the old feuds are disrupted at least for the time being.

For some purposes, however, it is most effective to get away from the family group completely. One reason we speak of harried housewives but not of harried husbands is that wives (and especially mothers) are so often tied down to the four walls and the four faces of the home. The piling-up of petty irritations into peaks of tension results in perennial irritability and conflict-proneness. Then little issues provoke major crises because of the loading of accumulated tension.

Under these circumstances escape mechanisms are not childish but sensible. Getting out of the house produces a sense of relief. A television farce or romance produces the right kind of distraction. Even "going home to mama" may be useful provided mama does not take daughter's troubles too seriously.

There may be corresponding value in masculine and children's expeditions. The husband's "night out with the boys" may be resented by his wife but is likely to result in a new look in marital relations. And the children need not always be on the receiving end for personnel changes but may find welcome escape from the network of conflict by visiting their friends in return.

There is also what the psychologists call "catharsis"-the reduction of tension through telling one's troubles to someone else. There is little doubt that "unloading" one's difficulties on someone else genuinely lightens the burden of conflict for most people. In so doing, it reduces the necessity for purposeless vindictiveness which prolongs the conflict. In effect, catharsis (like the other safety valves) helps to break the vicious circle of attack and retaliation which so often characterizes families with a long history of conflict.

The only problem involved in the use of catharsis is the selection of the target. Among the shoulders which might conveniently be cried on are those of the husband (provided he is not the antagonist in the conflict), the mother, and the neighbor. Providing a sympathetic ear for the spouse is one of the major steps in accomplishing what I like to call the "mental hygiene function" of marriage. Mothers and neighbors can usually be counted on to be sympathetic-but sometimes too much so, tending to jump into the conflict, too, starting a mobilization race on both sides.

Because of these dangers in lay friendships, couples in serious conflict sometimes find it useful to turn to a professional third party, for instance, a clergyman, doctor, or family counselor. These functionaries are accustomed to providing people with discreet opportunities for catharsis.

Whatever the specific safety valve opened, the reduction of the head of steam facilitates the tolerance of frustration and a patient approach to finding satisfactory solutions to the basic sources of conflict. 


\section{Processes of Resolving Family Conflict}

So far we have been ducking the main issue of what happens when two parties to a family conflict collide head-on. To treat this problem, it is necessary to assume that the two partners (for it is most often the husband and wife who find themselves in this position) think of each other as equals. Hence the problem cannot be solved by appeal to differential authority.

One obstacle to resolving family conflict is that it is often dyadic in nature. Hence voting is impossible. Or at least there is no way to break the inevitable tie. Some families have found that conflicts of limited importance can be settled by ordinary voting procedures-especially if there is an odd number of children in the family. But this easy way out is available at best during a small fraction of the total family life-cycle.

What, then, to do in case of a deadlock?

\section{DISCUSSION}

The natural first step is to talk things over, to outline the various possible solutions, to weigh the pros and cons in an attempt to arrive at some sort of solution. This process of decision-making has been studied and analyzed too well elsewhere to need detailed treatment here (1, pp. 225-51). Suffice it to say that there are three major types of solutions which can be reached: (1) consensus-that is, mutual agreement by both partners that a vacation at the lake would be best for both of them; (2) compromise-one week at the lake and one week in the mountains so that both partners gain part and lose part of their objectives; (3) concession-two weeks in the mountains, not because the wife is convinced that that would be most enjoyable, but because she decides to end the conflict by dropping her own demands.

Most families solve most of their problems by such processes of communication followed by decision-making.

\section{MEDIATION}

Occasionally, couples need outside help in arriving at a decision. Here relatives and friends can seldom qualify because they are usually more closely aligned with one partner than the other. Hence professional personnel are almost the only resort.

The function of the third party in this case is seldom to take over the decision-making process. Rather he acts as a catalytic agent, enabling the couple to become more objective and more rational by his very presence. If conflict is serious and hostile feelings have accumulated, he may work with each partner separately for a long time. Only after selfinsight and mutual empathy have been achieved might it be productive for the couple to be seen jointly. Meanwhile the couple may discover on their own that they have already acquired the ability to settle their conflict, aided by the new skills and understandings gained in counseling. Even when only one partner turns to a third party, the beneficial repercussions of the counselor's collaboration may be felt throughout the family.

\section{ACCOMMODATION}

In one sense, accommodation might be listed as a type of decision. More accurately, however, it represents the recognition of a failure to agree. In the classic phrase, we "agree to disagree" or to "live and let live." In the specific case of the summer vacation, this could mean separate vacations for husband and wife (though so much autonomy runs heavily counter to American mores).

It is not always possible for the parties to a family conflict to go their separate ways. If the issue at hand is the need for a new car, one either gets one or one does not. But if John likes to play tennis while Mary likes to go to concerts, Mary could accommodate 
herself to going it alone while John finds a different partner.

Essentially, accommodation involves adopting a philosophical attitude of resignationcoming to the conclusion that further attempts to influence the partner are just not worth the conflict they provoke. Hence expectations of mutuality are abandoned in favor of accepting the partner as he is.

\section{SEPARATION}

If neither discussion, mediation, nor accommodation succeeds in settling family conflict, the last resort is separation. In a sense, separation does not really settle conflict at all, but it usually does end it. If the antagonists are no longer within shooting distance of each other, their attention is soon likely to be diverted from the point at issue.

The term "separation" is usually applied to husband and wife. If they cannot live together in peace, few there are who would force them to go on living in conflict. Even those groups who are most opposed to divorce and remarriage recognize that separating the marriage partners is sometimes preferable to prolonging the agony.

Separation can also occur between parents and children. The military academies of this country are populated by boys whose parents were unable to arrive at peace treaties with them. And the older adolescent who leaves home for college, job, or marriage sometimes only thus terminates his or her revolutionary war.

Separation is the most drastic way out of family conflict, yet those who have tried it often say that peaceful loneliness is an improvement over perpetual conflict.

\section{Conclusion}

Returning now to the question of the similarities and differences between family conflict and conflict in other settings, it is apparent that the sources of family conflict are largely distinctive. Families are uniquely small and intimate. The structure and developmental tasks of the family are transformed with unusual speed. Only in the involuntary nature of world society is there a close analogy.

Much as the sources of conflict may differ between the family and the world community, the mechanisms for preventing and resolving conflict have more in common. International "mechanisms of avoidance" include the United Nations Emergency Force sealing the border between Israel and Egypt and the proposals for disengagement in Central Europe. The "allocation of authority" to a world court and a world government would alter the naked struggle of sovereign nations among themselves. "Equality of treatment" is just as difficult a problem among nations differing in size, wealth, and maturity as among children differing in age. However, the admission of all nations to membership in the United Nations might achieve minimal equality and bring excluded nations within the sphere of authority of the international organization. Rotation systems in key international offices tend to reduce international jealousy.

"Increased facilities" for international living are provided through economic development, reducing the envy of the "have" nations by the have-nots. "Priority systems" for the use of limited facilities apply to such international waterways as rivers and harbors on which multiple countries depend. "Enlargement of areas of autonomy" reduces international conflict as colonial powers become independent. International "safety valves" include the opportunities for catharsis provided by the open forum of the General Assembly and by smaller-scale talks at or below the summit. 
Big-power rivalry between East and West is closely analogous to the conflict between husband and wife. Voting has little value when the conflicting parties perennially deadlock or veto each other. The focus under such circumstances must be on the same processes that enable families to resolve their deadlocks. Discussion through negotiation and diplomatic talks may lead to consensus, compromise, or concession internationally as well as familially. The General Secretary of the United Nations has increasingly become an international mediator, as have many of the smaller powers. Accommodation to the status quo has been the outcome of many an international crisis that for a time threatened to disturb the peace. But separation, in a shrinking world, is one process not open to national societies, for, much as they may dislike each other, they must go on forever living in the same international "house."

\section{REFERENCES}

1. BLOOD, Robert O., JR. Anticipating Your Marriage. Glencoe, Ill.: Free Press, 1955.

2. Blood, Robert O., JR., and Wolfe, Donald M. Husbands and Wives: The Dynamics of Married Living. Glencoe, Ill.: Free Press, 1960.

3. Bowman, Henhy A. Marriage Education in the Colleges. New York: American Social Hygiene Association, 1949.

4. Burgess, Ernest W., and Wallin, Paul. Engagement and Marriage. Philadelphia: J. B. Lippincott Co., 1953.

5. Glick, Paul. "The Life Cycle of the Family," Marriage and Family Living, XVII (1955), 3-9.

6. Landis, Judson T. "Marriages of Mixed and Non-mixed Religious Faith," American Sociological Review, XIV (1949), 401-7.

7. Murdock, George P. Social Structure. New York: Macmillan Co., 1949.

8. Parsons, Talcott. "The Social Structure of the Family." In Ruth NANDA ANSHEN (ed.), The Family: Its Function and Destiny. New York: Harper \& Bros., 1949. 